\title{
Article \\ Preoperatively Treated Diffuse-Type Gastric Adenocarcinoma: Glucose vs. Other Energy Sources Substantially Influence Prognosis and Therapy Response
}

\author{
Ahmed A. Abdelhakeem ${ }^{1}$ (D), Xuemei Wang ${ }^{2}$, Rebecca E. Waters ${ }^{3}$, Madhavi Patnana ${ }^{4}$, Jeannelyn S. Estrella ${ }^{3}$, \\ Mariela Blum Murphy ${ }^{1}$, Allison M. Trail ${ }^{1}$, Yang Lu ${ }^{5}$, Catherine E. Devine ${ }^{4}$, Naruhiko Ikoma ${ }^{6}$, Prajnan Das ${ }^{7}$, \\ Brian D. Badgwell ${ }^{6}$, Jane E. Rogers ${ }^{8}$ and Jaffer A. Ajani ${ }^{1, *}$
}

check for updates

Citation: Abdelhakeem, A.A.; Wang, X.; Waters, R.E.; Patnana, M.; Estrella, J.S.; Blum Murphy, M.; Trail, A.M.; Lu, Y.; Devine, C.E.; Ikoma, N.; et al. Preoperatively Treated Diffuse-Type Gastric Adenocarcinoma: Glucose vs. Other Energy Sources Substantially Influence Prognosis and Therapy Response. Cancers 2021, 13, 420. https://doi.org/10.3390/ cancers 13030420

Received: 11 November 2020 Accepted: 21 January 2021 Published: 23 January 2021

Publisher's Note: MDPI stays neutral with regard to jurisdictional claims in published maps and institutional affiliations.

Copyright: (c) 2021 by the authors. Licensee MDPI, Basel, Switzerland. This article is an open access article distributed under the terms and conditions of the Creative Commons Attribution (CC BY) license (https:/ / creativecommons.org/licenses/by/ $4.0 /)$.
1 Department of Gastrointestinal Medical Oncology, The University of Texas MD Anderson Cancer Center, Houston, TX 77030, USA; aaabdelhakeem@mdanderson.org (A.A.A.); mblum1@mdanderson.org (M.B.M.); atrail@mdanderson.org (A.M.T.)

2 Department of Biostatistics, The University of Texas MD Anderson Cancer Center, Houston, TX 77030, USA xuewang@mdanderson.org

3 Department of Anatomical Pathology, The University of Texas MD Anderson Cancer Center, Houston, TX 77030, USA; rwaters@mdanderson.org (R.E.W.); jsestrella@mdanderson.org (J.S.E.)

4 Department of Abdominal Imaging, The University of Texas MD Anderson Cancer Center, Houston, TX 77030, USA; madhavi.patnana@mdanderson.org (M.P.); catherine.devine@mdanderson.org (C.E.D.)

5 Department of Nuclear Medicine, The University of Texas MD Anderson Cancer Center, Houston, TX 77030, USA; ylu10@mdanderson.org

6 Department of Surgical Oncology, The University of Texas MD Anderson Cancer Center, Houston, TX 77030, USA; nikoma@mdanderson.org (N.I.); bbadgwell@mdanderson.org (B.D.B.)

7 Department of Radiation Oncology, The University of Texas MD Anderson Cancer Center, Houston, TX 77030, USA; prajdas@mdanderson.org

8 Pharmacy Clinical Programs, The University of Texas MD Anderson Cancer Center, Houston, TX 77030, USA; jerogers@mdanderson.org

* Correspondence: jajani@mdanderson.org; Tel.: +1-713-792-2828; Fax: +1-713-563-9192

Simple Summary: The diffuse type of gastric adenocarcinoma (dGAC) generally confers a poor prognosis compared to intestinal type. Some dGACs are not avid on fluorine-18 fluoro-2-deoxy-D-glucose PET (FDG-PET) while others seem to consume glucose avidly. We analyzed the outcomes based on the avidity of the primary on baseline FDG-PET. Our data suggest that if dGACs used glucose as an energy source then the prognosis was very poor while non-glucose sources improved prognosis. Multi-platform (including metabolomics) profiling of dGACs would yield useful biologic understanding.

Abstract: Diffuse type of gastric adenocarcinoma (dGAC) generally confers a poor prognosis compared to intestinal type. Some dGACs are not avid on fluorine-18 fluoro-2-deoxy-D-glucose PET (FDG-PET) while others seem to consume glucose avidly. We analyzed the outcomes based on the avidity (high with standardized uptake value $(\mathrm{SUV})>3.5$ or low with $\mathrm{SUV} \leq 3.5)$ of the primary on baseline FDG-PET. We retrospectively selected 111 localized dGAC patients who had baseline FDG-PET (all were treated with preoperative chemotherapy and chemoradiation). FDG-PET avidity was compared with overall survival (OS) and response to therapy. The mean age was 59.4 years and with many females (47.7\%). The high-SUV group (58 (52.3\%) patients) and the low-SUV group (53 (47.7\%) patients) were equally divided. While the median OS for all patients was 49.5 months (95\% CI: 38.5-98.8 months), it was 98.0 months (95\% CI: 49.5-NE months) for the low-SUV group and 36.0 months for the high-SUV ( $p=0.003)$. While the median DFS for all patients was 38.2 months (95\% CI: 27.7-97.6 months), it was 98.0 (95\% CI: 36.9-NE months) months for the low-SUV group was and only 27.0 months (95\% CI: 15.2-63.2 months) for the high-SUV group $(p=0.005)$. Clinical responses before surgery were more common in the low-SUV group but overall we observed only 4 pathologic complete responses in 111 patients. Our unique data suggest that if dGACs used glucose as an energy source then the prognosis was very poor while non-glucose sources improved prognosis. Multi-platform (including metabolomics) profiling of dGACs would yield useful biologic understanding. 
Keywords: FDG; PET; prognosis; diffuse gastric cancer

\section{Introduction}

Gastric adenocarcinoma (GAC) is the third leading cause of cancer-related deaths and ranks as the fifth most common cancer worldwide [1]. GAC represents $95 \%$ of all types of gastric cancers and is divided into two major subtypes: intestinal type (iGAC) and diffuse type (dGAC) with or without signet ring cells (SRCs) [2,3]. dGAC was relatively less frequently seen (32\%) in the past compared to iGAC (54\%) but its incidence has been rising alarmingly [4]. It is more frequently seen in females, younger individuals, and Blacks $[4,5]$. dGAC lacks the intercellular adhesion molecules and therefore, GAC cells do not form glands and often are dispersed as single cells or small clusters surrounded by fibrous stroma [4]. SRCs are unique in that they have abundant intra-cytoplasic mucin resulting in a nucleus shift near the cell wall giving it a "ring" appearance [6]. Little is known about SRCs in terms of their molecular biology; however, the presence of SRCs is associated with poor prognosis [7-16]. Only a small proportion (1-3\%) of dGACs has been linked to germline mutations of $C D H 1$ leading to hereditary cancers [16]. For initial GAC staging, Fluorine-18 fluoro-2-deoxy-D-glucose PET-computed tomography (FDG-PET/CT) has no established role in GAC but it may be helpful to detect occult metastases [17]. FDG-PET/CT might provide additional information about the primary GAC that may be of use to clinicians and operating surgeons as dGACs tend to extend submucosally [18]. FDG-PET/CT may be also useful in differentiating dGAC subtypes [19] as the prognosis of dGAC patients is varied. The potentially low FDG avidity in dGAC is attributed to several factors, including the low-density diffuse infiltration of GAC cells, existence of extracellular or intracellular metabolically inert mucus content, use of glutamine as fuel rather than glucose, and low expression level of glucose transporter 1 (GLUT-1) [20,21]. Low avidity on PET has been reported as a beneficial prognosticator in dGAC patients who had primary surgery [22]. In the West, preoperative therapy is commonly given for localized GACs (including dGACs), we chose to determine the value of baseline FDGPET in localized dGACs treated preoperatively as reported before [23]. In this study, we assessed the correlation between FDG-PET/CT avidity at baseline (prior to any treatment) and survival of preoperatively treated dGAC patients.

\section{Patients and Methods}

We retrospectively identified localized dGAC patients treated at the University of Texas MD Anderson Cancer Center from our prospectively maintained databases between January 2005 and February 2019. Selected patients had an untreated localized (stage I to III) dGAC and a baseline PET-CT along with other staging to include endoscopic ultrasonography, laparoscopy, and blood work. Additionally, we collected demographics (age, sex, and ethnicity), Eastern Cooperative Oncology Group (ECOG) performance status, baseline body mass index (BMI), histologic grade and histologic subtype by the Lauren's classification. Nearly all patients had chemotherapy and chemoradiation prior to surgery as previously reported [23]. Treatment and outcomes included overall survival (OS), progression-free survival (PFS) from the start of treatment, and best response. In each patient, we reviewed the standardized uptake values (SUV) maximum of the primary tumor. No other selection criteria were used.

\section{Statistical Analysis}

OS was defined as the time interval between the first treatment date and death date or the surviving patients were censored at the last follow-up date. Disease-free survival (DFS) was defined as the time from the first treatment date to first progression date or death date, whichever came first, or the patients without progression were censored at the last follow-up date. Clinical Complete Response (cCR) was defined as resolution of the 
primary lesion including nodes on PET-CT or no evidence of progression on CTs along with negative endoscopic biopsy as described previously [8] but localized GACs are not amenable to standard response criteria used for advanced GACs [24,25].

The Kaplan-Meier method was used to estimate OS/DFS. The Fisher's exact test was used to assess the difference in pathologic response rate between the high vs. low SUV groups. Statistical analyses were performed using SAS 9.4.(The SAS Institute, Cary, NC, USA).

The pathologic complete response (pCR) was defined as having no residual cancer cells in the entire specimen (primary and nodes) [11].

\section{Results}

A total of 111 patients were included in this project. Demographics and clinical characteristics are summarized in Table 1. The mean age was 59.4 years, with a large female cohort (47.7\%). Most patients had an ECOG performance status of $1(56.8 \%)$ or 0 $(38.7 \%)$ while the remaining $4.5 \%$ had ECOG status equal to $>1$. All patients had dGAC. Histopathology confirmed that $100(90 \%)$ patients' dGAC contained SRCs, $10(9 \%)$ were not specified, and only one case $(0.9 \%)$ was mixed mucinous type with SRCs.

Table 1. Demographic and clinical characteristics of patients.

\begin{tabular}{|c|c|c|}
\hline Clinical Feature & Low SUV Group $(N, \%)$ & High SUV Group $(N, \%)$ \\
\hline Total Number of cases & 53 & 58 \\
\hline Age (mean \pm SD) & $59.5 \pm 11.56$ & $59 \pm 13.94$ \\
\hline \multicolumn{3}{|l|}{ Race } \\
\hline White or Caucasian & $29(54.7 \%)$ & $28(48.3 \%)$ \\
\hline Black or African American & $6(11.3 \%)$ & $7(12 \%)$ \\
\hline Asian & $6(11.3 \%)$ & $4(6.9 \%)$ \\
\hline Other & $12(22.7 \%)$ & $19(32.8 \%)$ \\
\hline \multicolumn{3}{|l|}{ Sex } \\
\hline Male & $23(43.4 \%)$ & $35(60.3 \%)$ \\
\hline Female & $30(56.6 \%)$ & $23(39.7 \%)$ \\
\hline \multicolumn{3}{|l|}{ Performance Status (ECOG) } \\
\hline 0 & $24(45.3 \%)$ & $19(32.8 \%)$ \\
\hline 1 & $28(52.8 \%)$ & $35(60.3 \%)$ \\
\hline 2 & $1(1.9 \%)$ & $3(5.2 \%)$ \\
\hline 3 & 0 & $1(1.7 \%)$ \\
\hline \multicolumn{3}{|l|}{ Location of tumor } \\
\hline Antrum & $13(25 \%)$ & $14(24.6 \%)$ \\
\hline Antrum and Pyloric Canal & $0(0.0 \%)$ & $1(1.8 \%)$ \\
\hline Body & $20(38.5 \%)$ & $15(26.3 \%)$ \\
\hline Body and Antrum & $2(3.8 \%)$ & $1(1.8 \%)$ \\
\hline Cardia & $14(26.9 \%)$ & $20(35.1 \%)$ \\
\hline Cardia, Body and Antrum & $2(3.8 \%)$ & $3(5.3 \%)$ \\
\hline Fundus & $1(1.9 \%)$ & $0(0.0 \%)$ \\
\hline Fundus and Body & $0(0.0 \%)$ & $1(1.8 \%)$ \\
\hline Pyloric Canal & $0(0.0 \%)$ & $2(3.5 \%)$ \\
\hline \multicolumn{3}{|l|}{ Tumor differentiation } \\
\hline Poorly differentiated & $53(100 \%)$ & $58(100 \%)$ \\
\hline \multicolumn{3}{|l|}{ Adenocarcinoma subtype } \\
\hline Signet Ring Carcinoma & $48(90.5 \%)$ & $53(91.4 \%)$ \\
\hline Not Signet Ring Carcinoma & $5(9.5 \%)$ & $5(8.6 \%)$ \\
\hline \multicolumn{3}{|l|}{ Tumor Histology } \\
\hline Diffuse & $53(100 \%)$ & $58(100 \%)$ \\
\hline \multicolumn{3}{|l|}{ Baseline $\mathrm{T}$ stage } \\
\hline Tis & 0 & $1(1.7 \%)$ \\
\hline $\mathrm{T} 1$ & $12(22.6 \%)$ & $1(1.7 \%)$ \\
\hline $\mathrm{T} 2$ & $15(28.3 \%)$ & $9(15.5 \%)$ \\
\hline T3 & $25(47.2 \%)$ & $39(67.3 \%)$ \\
\hline $\mathrm{T} 4$ & $1(1.9 \%)$ & $8(13.8 \%)$ \\
\hline
\end{tabular}


Table 1. Cont.

\begin{tabular}{ccc}
\hline Clinical Feature & Low SUV Group $(N, \%)$ & High SUV Group (N, \%) \\
\hline Baseline N stage & & \\
N0 & $40(75.5 \%)$ & $31(53.5 \%)$ \\
N1 & $9(16.9 \%)$ & $16(27.6 \%)$ \\
N2 & $2(3.8 \%)$ & $8(13.7 \%)$ \\
N3 & $2(3.8 \%)$ & $3(5.2 \%)$ \\
Baseline M & & \\
M0 & $53(100 \%)$ & $53(1005)$ \\
Baseline clinical stage & & $1(1.7 \%)$ \\
0 & 0 & $8(13.8 \%)$ \\
I & $25(47.2 \%)$ & $2(3.5 \%)$ \\
IIA & $2(3.8 \%)$ & $22(37.9 \%)$ \\
IIB & $15(28.3 \%)$ & $25(43.1 \%)$ \\
III & $11(20.7 \%)$ & $33(56.9 \%)$ \\
Response to First-Line Therapy & & $14(24.1 \%)$ \\
Complete response & $43(81.1 \%)$ & $2(3.5 \%)$ \\
Partial response & $6(11.3 \%)$ & $9(15.5 \%)$ \\
Stable disease & $1(1.9 \%)$ & \\
Progressive disease & $3(15.5 \%)$ &
\end{tabular}

NOS, not otherwise specified; ECOG, Eastern Cooperative Oncology Group.

Patients were classified into two groups according to the level of SUV avidity of the primary lesion in the baseline PET-CT: the high-SUV $(>3.5)$ group included $58(52.3 \%)$ patients (Figure 1), and the low-SUV ( $\leq 3.5)$ group included $53(47.7 \%)$ patients (Figure 2$)$.

Forty-three $(81.1 \%)$ patients in the low-SUV group had a cCR, six (11.3\%) patients had some response while the remaining four (7.6\%) patients had either stable or progressive dGAC. Among the high-SUV group of patients, 33 (56.9\%) patients had cCR, $14(24.1 \%)$ patients had some response but 11 patients $(18.8 \%)$ had either stable or progressive dGAC. Despite having a higher rate of $\mathrm{CCR}$ among the low-SUV group compared to the high-SUV group $(81.1 \%$ vs. $56.9 \%, p=0.008)$, the difference in the rate of any response was not significant $(92.5 \%$ vs. $81.0 \% ; p=0.10)$.

The median OS for the entire cohort was 49.5 months (95\% CI: 38.5-98.8 months) Figure 3.

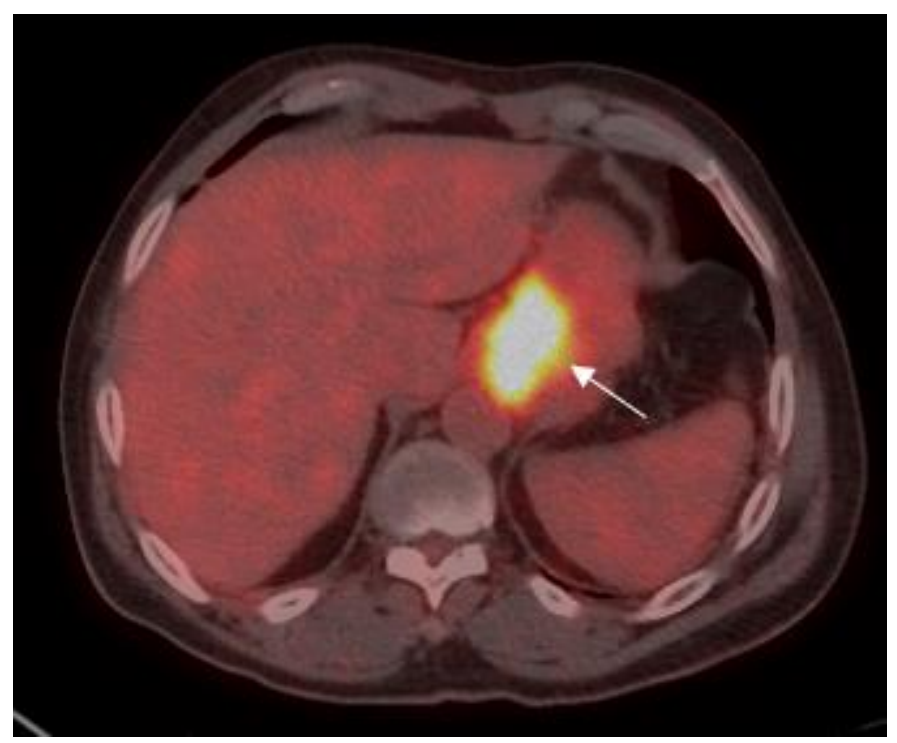

Figure 1. A 70-year old male with gastric adenocarcinoma (SRCC). Axial PET-CT images show low ${ }^{18}$ F-fluorine-18 fluoro-2-deoxy-D-glucose (FDG) uptake (standardized uptake value (SUV) max: 16.2) in primary tumor in the body of the stomach (white arrow). 


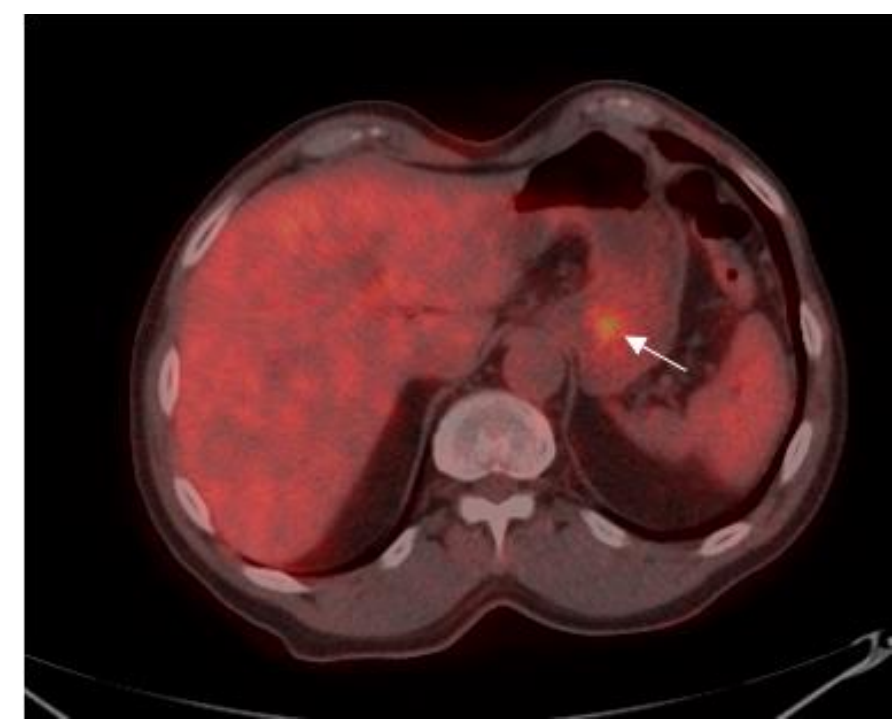

Figure 2. 75-year old male with gastric adenocarcinoma (SRCC). Axial PET-CT images show low ${ }^{18}$ F-FDG uptake (SUV max: 3.5 ) in primary tumor in the body of the stomach (white arrow).

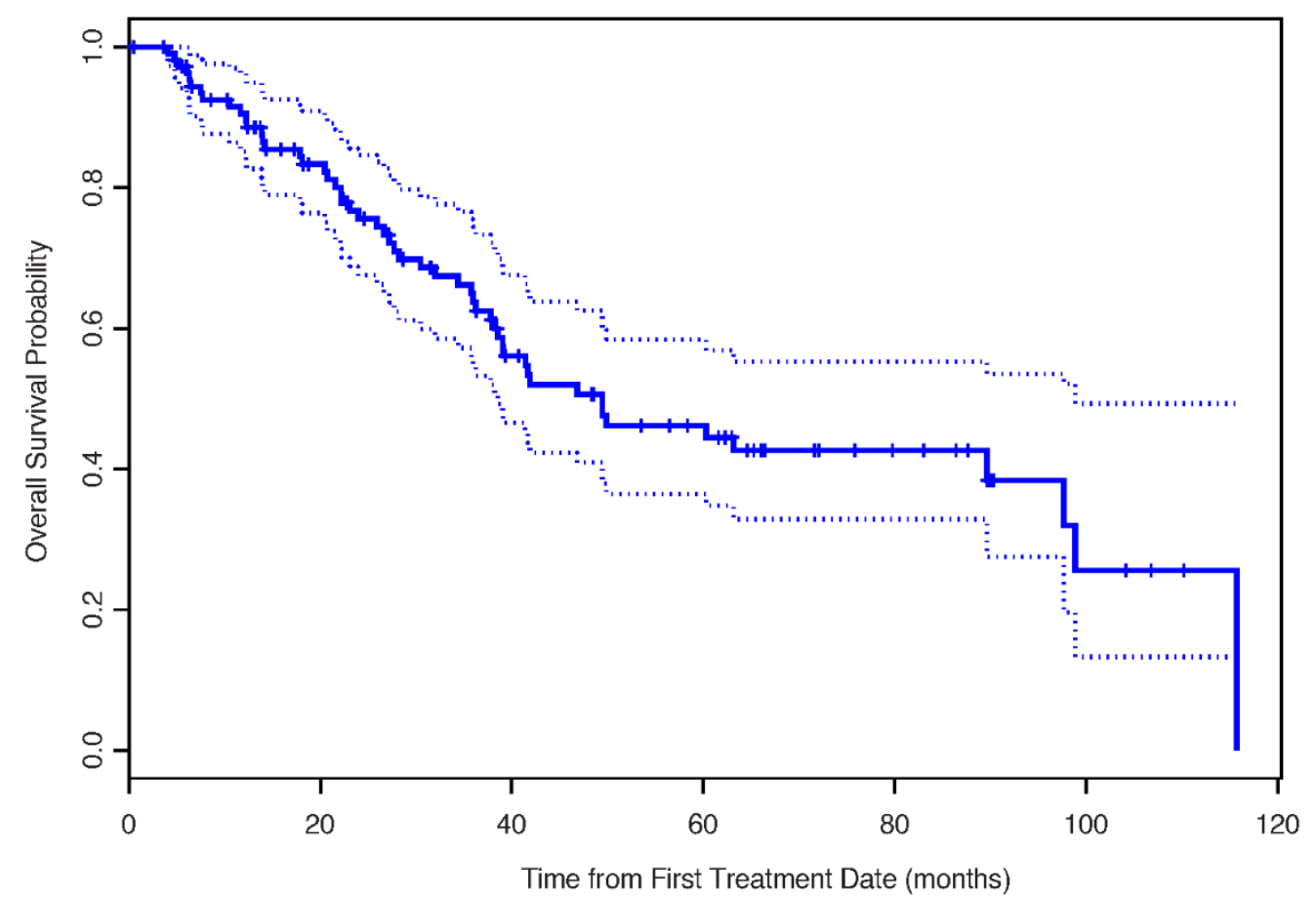

Figure 3. The Kaplan-Meier estimates for overall survival.

The median OS for the low-SUV group was 98.0 months (95\% CI: 49.5, not estimable (NE) months) and that for the high-SUV group was only 36.0 months ( $p=0.003$ ) (Figure 4 ).

The median DFS for the entire cohort was 38.2 months (95\% CI: 27.7-97.6 months) The median DFS for the low-SUV group was 98.0 months (95\% CI: 36.9-NE months) compared to only 27.0 months (95\% CI: 15.2-63.2 months) for the high-SUV group ( $p$ value $=0.005$ ). Of the 100 patients with SRCs in untreated samples, 48 patients were in the low-SUV group and 52 patients were in the high-SUV group. Post-treatment pathological specimens were assessed for SRC enrichment. Thirty (62.5\%) patients in the low-SUV group and $29(55.76 \%)$ patients in the high-SUV group had persistent SRCs. Further analysis of post-treatment SRC in the low-SUV group based on AJCC 8th edition [26] showed that a higher SRC percentage was noted when the stage (ypTNM) was higher than ypT1N0M0 and when 
there was regional lymph node(s) metastasis compared to the ypT0N0M0 and ypT1aN0M0 groups (Figure 5). The findings were the same for the high-SUV group (Figure 6). Only four $(3.6 \%)$ patients achieved a pCR. One (1.9) pCR patient was in the low SUV group and three $(5.3 \%)$ were in the high SUV group (not significant).

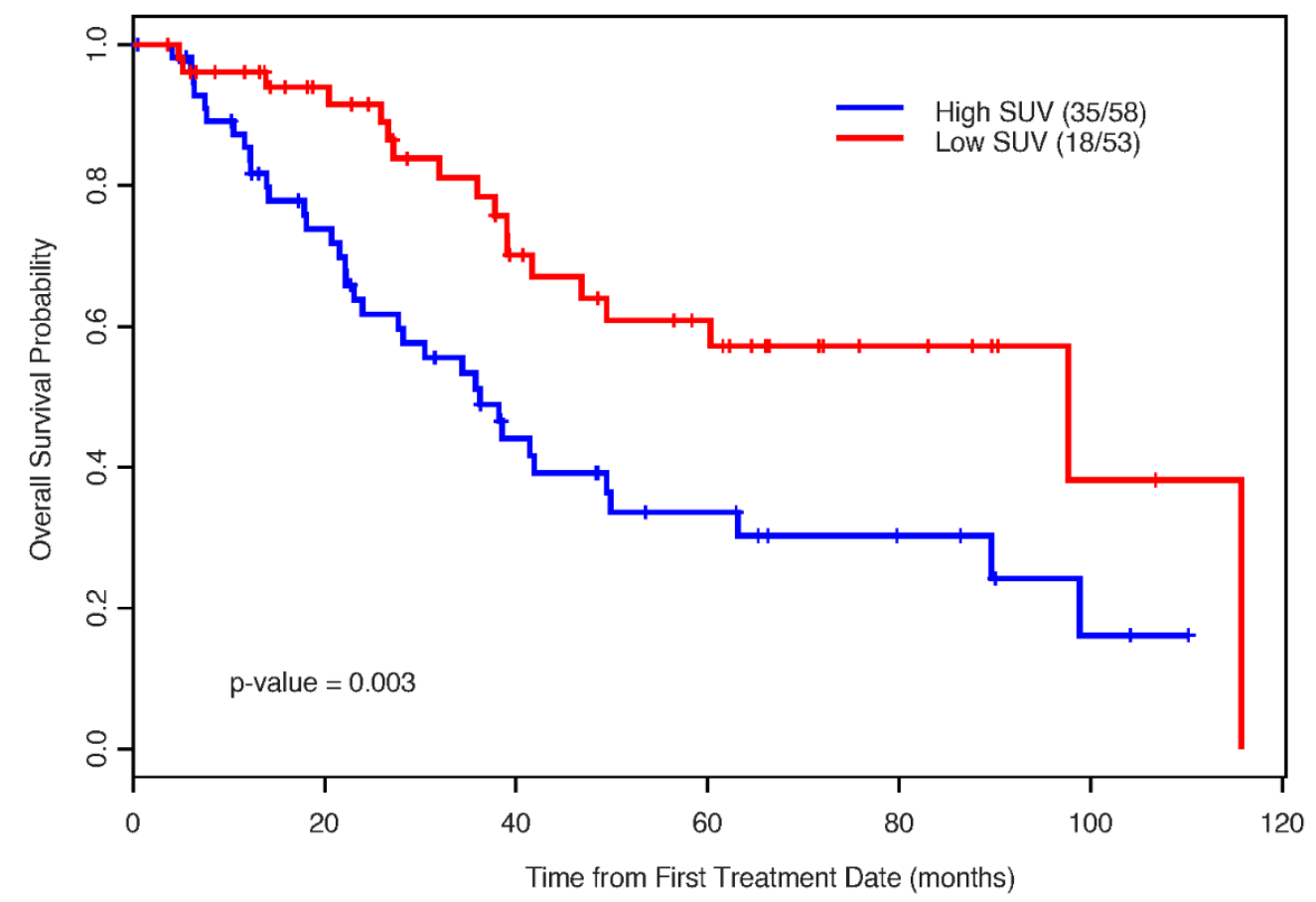

Figure 4. The Kaplan-Meier estimates for overall survival by SUV status.
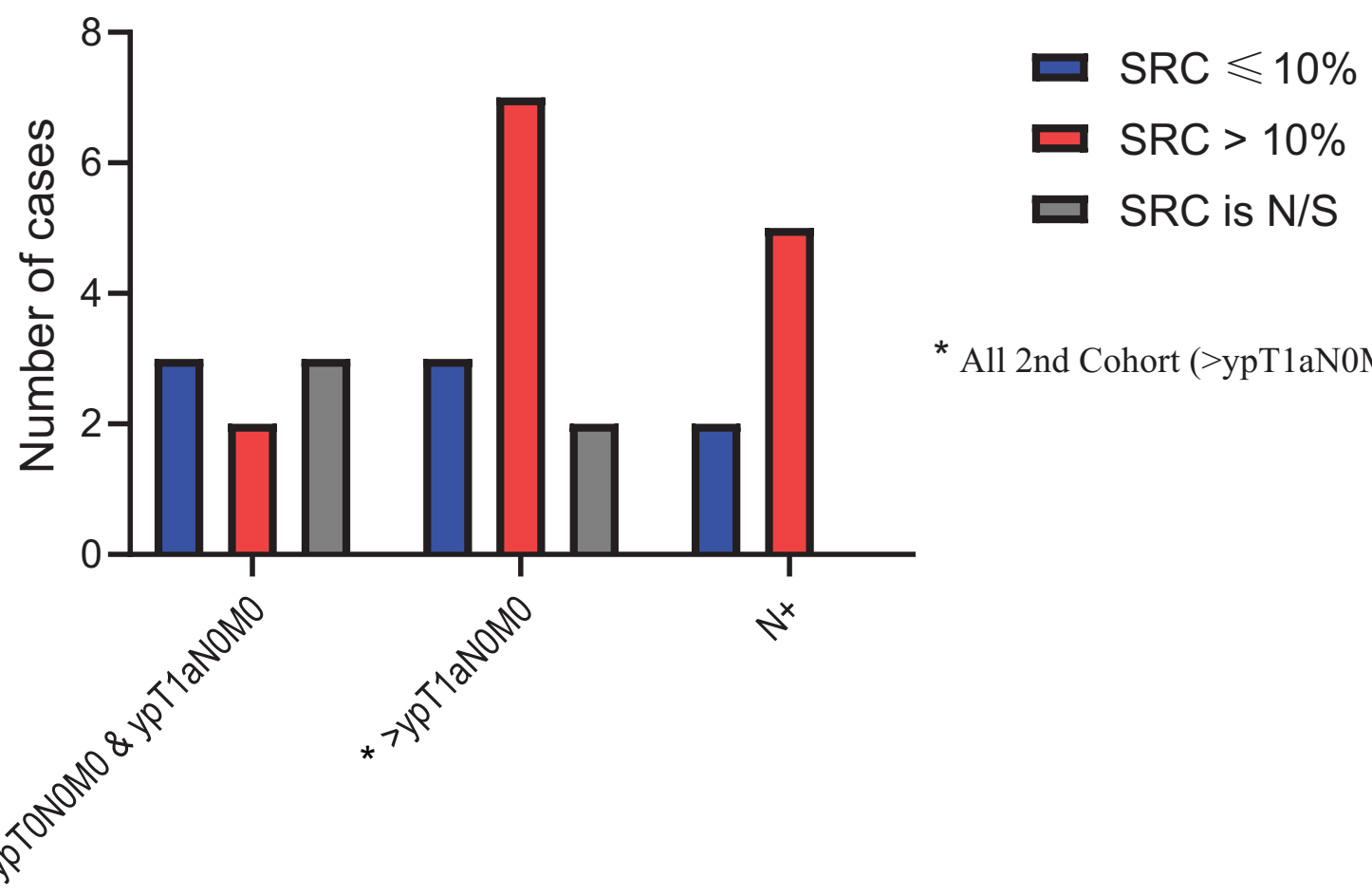

${ }^{*}$ All 2nd Cohort (>ypT1aN0M0) cases are N0

Figure 5. Post treatment signet ring cells (SRC) percentage distribution in Low-SUV group. 


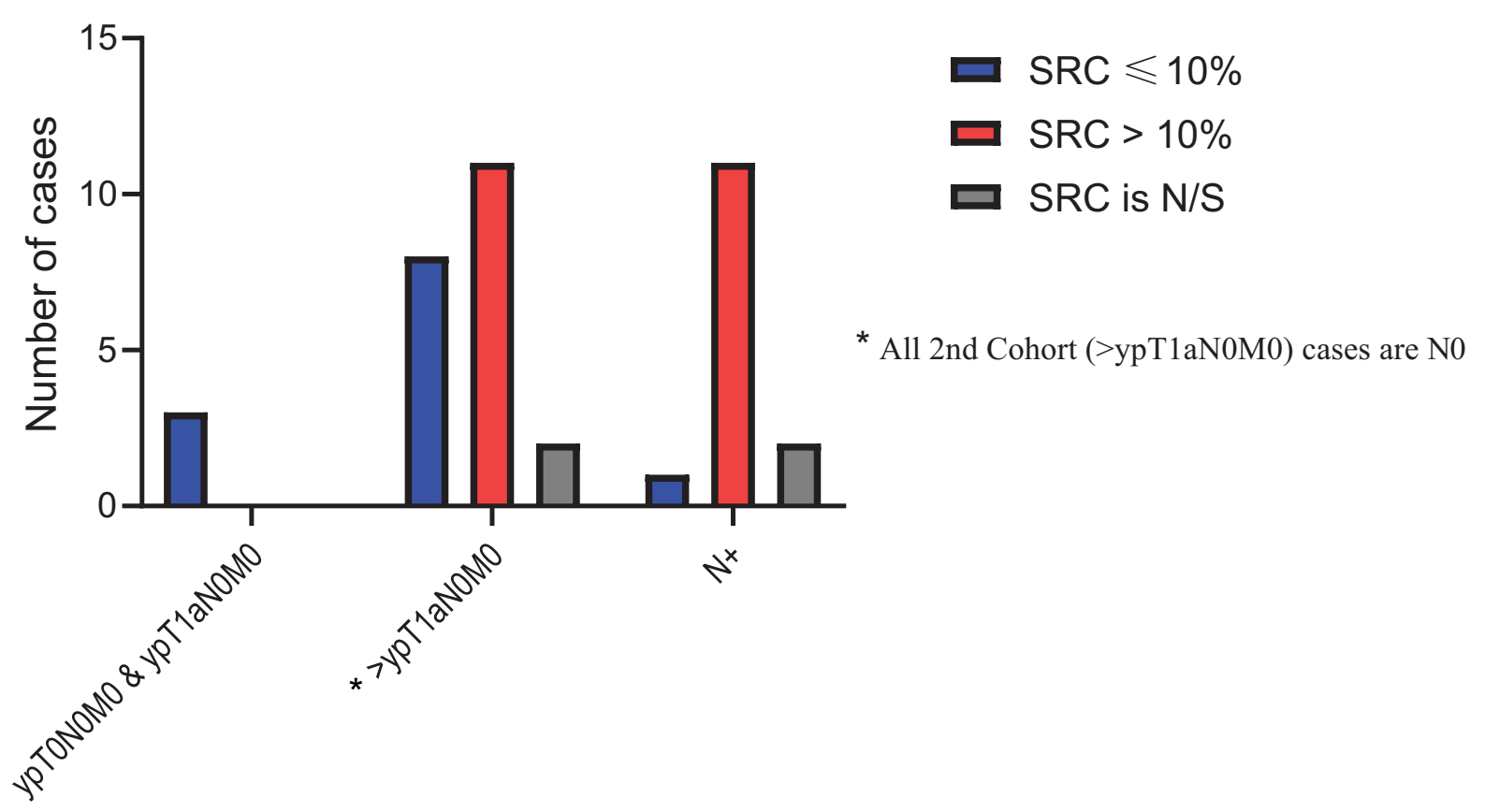

Figure 6. Post treatment SRC percentage distribution in High-SUV group.

\section{Discussion}

GAC is a major health burden with $>1$ million new cases/year globally. In the USA, 26,240 new cases are expected in $2020[14,27,28]$. It is the leading cause of cancer deaths in 10 countries [29]. Most patients are diagnosed in the late stages [14] and have an OS of $<12$ months. dGACs are poorly differentiated with the worst OS $[3,14]$. Others and our group have previously reported that dGACs are associated with resistance to therapy and short OS [10-13,30,31]. The incidence of poorly differentiated tumors and dGACs has been rising [4]. It is interesting that dGAC incidence has been rapidly rising in Blacks for reasons that are entirely unclear [4]. Therapeutic options are limited and mainly empiric [14]. Nevertheless, GACs are heterogenous and even dGACs can have varied outcomes. Clinical variables are not discriminating of the outcome but at the same time, we must acknowledge that we do not have different therapies for those who are likely to fare better and those who are likely to have rather rapid progression.

PET-CT is a useful tool and has shown promise in esophageal cancer [32]. The utility of PET-CT in GAC as a whole is not established. Some dGACs are known not to be avid on PET-CT at the outset. A decreased number of GLUT1 receptors may be one of the reasons but also some adenocarcinoma cells reprogram their metabolism to utilize glutamine as an energy source. What disadvantage glutamine might provide is under study. However, it is not clear if such a switch in the metabolism can change the clinical responsiveness and prognosis of the patients. There are no easy answers to such questions. We have asked a very simple question in which we tried to correlate the baseline SUV on PET-CT with prognosis and response to therapy. Our results may not be considered unique but they are certainly intriguing. There are no reports in the literature that are focused solely on these questions for preoperatively treated dGACs. We found that the prognosis of patients in the low SUV group was rather excellent (median OS $=98$ months) but patients in the high SUV group did poorly (meaning glucose as an energy source improved fitness of cancer cell over the use of glutamine). Perhaps the next step could be to learn the biology of these groups at the molecular level.

The major drawback of our study is the retrospective nature of the project and another limiting but essential factor is that we could select only those dGAC patients who had baseline PET-CT. We were not able to balance patients in the low and high SUV groups. A validation of our finding is desired. There are only two studies that seem to address the role 
of PET-CT in GAC. An excellent study by Chon $\mathrm{H}$ et al. [22]. focused on 727 localized GAC patients who underwent surgery as primary therapy but all had baseline FDG-PET [22]. They also found that in the subset of patients with dGAC or SRC, high SUV leads to poor OS but the SUV avidity does not affect outcome in well/moderately differentiated GACs, even poorly differentiated GACs, or iGACs. Their results in dGACs/SRCs mimic ours except in the context that all our patients were pre-treated and most received chemotherapy followed by chemoradiation before surgery. Their study and our results convey a combined message that the altered metabolism of dGAC plays a role throughout the course of illness and is a determinant of patient prognosis irrespective of the treatment strategy offered. Meaning, the aggressive phenotype of glucose consuming dGAC remains unaltered whether they have extensive preoperative therapy (our population) or they undergo surgery first and then receive adjuvant therapy [22]. Arslan E et al. [33] studied 339 patients who had FDGPET at baseline; however, only 102 patients were surgical candidates. Patients with SRC had low SUV plus this group had larger tumors, more frequent lymph node metastases. They did not provide prognostic data.

\section{Conclusions}

In conclusion, we demonstrated that in 111 localized dGAC patients who were mostly treated with chemotherapy followed by chemoradiation then surgery, high FDG SUV (glucose as a source of energy) conferred poor prognosis. All dGACs appear to have inherent therapy resistance and aggressive clinical behavior. Molecular biology of patients with dGAC with high or low SUV might shed light on how to strategize therapy in the future.

Author Contributions: All co-authors contributed to this study. Conceptualization, J.A.A. and A.A.A.; methodology, A.A.A., J.A.A., R.E.W. and J.S.E.; software, M.P., C.E.D., and Y.L.; validation, J.A.A. and A.A.A.; formal analysis, A.A.A. and X.W.; investigation, A.A.A.; resources, M.B.M., B.D.B., and N.I.; data curation, A.A.A. and J.A.A.; writing-original draft preparation, A.A.A., J.E.R., A.M.T. and J.A.A.; writing-review and editing, All authors; visualization, A.A.A., Y.L., and X.W.; supervision, J.A.A.; project administration, J.A.A. All authors have read and agreed to the published version of the manuscript.

Funding: The authors received no specific funding for this work.

Institutional Review Board Statement: The study was conducted according to the guidelines of the Declaration of Helsinki, and approved by the Institutional Review Board) of The University of Texas, M.D Anderson Cancer Center (protocol PA12-1063 and date of approval). Informed consent or a substitute form it was obtained from all patients included in the study.

Informed Consent Statement: Informed consent was obtained from all subjects involved in the study.

Data Availability Statement: The data presented in this study are available on request from the corresponding author.

Acknowledgments: Our research is supported by the NIH/NCI under award number P30CA016672.

Conflicts of Interest: The authors declare no conflict of interest.

\section{References}

1. Bray, F.; Ferlay, J.; Soerjomataram, I.; Siegel, R.L.; Torre, L.A.; Jemal, A. Global cancer statistics 2018: GLOBOCAN estimates of incidence and mortality worldwide for 36 cancers in 185 countries. CA Cancer, J. Clin. 2018, 68, 394-424. [CrossRef] [PubMed]

2. Patel, P.R.; Yao, J.C.; Hess, K.; Schnirer, I.; Rashid, A.; Ajani, J.A. Effect of timing of metastasis/disease recurrence and histologic differentiation on survival of patients with advanced gastric cancer. Cancer 2007, 110, 2186-2190. [CrossRef] [PubMed]

3. Ajani, J.A.; Abramov, M.; Bondarenko, I.M.; Shparyk, Y.; Gorbunova, V.; Hontsa, A.; Otchenash, N.; Alsina, M.; Lazarev, S.; Feliu, J.; et al. A phase III trial comparing oral S-1/cisplatin and intravenous 5-fluorouracil/cisplatin in patients with untreated diffuse gastric cancer. Ann. Oncol. 2017, 28, 2142-2148. [CrossRef] [PubMed]

4. Henson, D.E.; Dittus, C.; Younes, M.; Nguyen, H.; Albores-Saavedra, J. Differential trends in the intestinal and diffuse types of gastric carcinoma in the United States, 1973-2000: Increase in the signet ring cell type. Arch. Pathol. Lab. Med. 2004, 128, 765-770. [PubMed]

5. Hu, B.; El Hajj, N.; Sittler, S.; Lammert, N.; Barnes, R.; Meloni-Ehrig, A. Gastric cancer: Classification, histology and application of molecular pathology. J. Gastrointest. Oncol. 2012, 3, 251-261. 
6. Huntsman, D.G.; Carneiro, F.; Lewis, F.R.; MacLeod, P.M.; Hayashi, A.; Monaghan, K.G.; Maung, R.; Seruca, R.; Jackson, C.E.; Caldas, C. Early Gastric Cancer in Young, Asymptomatic Carriers of Germ-Line E-Cadherin Mutations. N. Engl. J. Med. 2001, 344, 1904-1909. [CrossRef]

7. Maru, D.M.; Khurana, H.; Rashid, A.; Correa, A.M.; Anandasabapathy, S.; Krishnan, S.; Komaki, R.; Ajani, J.A.; Swisher, S.G.; Hofstetter, W.L. Retrospective Study of Clinicopathologic Features and Prognosis of High-grade Neuroendocrine Carcinoma of the Esophagus. Am. J. Surg. Pathol. 2008, 32, 1404-1411. [CrossRef]

8. Harada, K.; Wu, C.C.; Wang, X.; Kaya, D.M.; Amlashi, F.G.; Iwatsuki, M.; Murphy, M.A.B.; Maru, D.M.; Weston, B.; Lee, J.H.; et al. Total Lesion Glycolysis Assessment Identifies a Patient Fraction With a High Cure Rate Among Esophageal Adenocarcinoma Patients Treated With Definitive Chemoradiation. Ann. Surg. 2019, 272, 311-318. [CrossRef]

9. Van Hootegem, S.J.M.; Smithers, B.M.; Gotley, D.C.; Brosda, S.; Thomson, I.G.; Thomas, J.M.; Gartside, M.; Van Lanschot, J.J.B.; Lagarde, S.M.; Wijnhoven, B.P.L.; et al. The Impact of Signet Ring Cell Differentiation on Outcome in Patients with Esophageal and Gastroesophageal Junction Adenocarcinoma. Ann. Surg. Oncol. 2019, 26, 2375-2384. [CrossRef]

10. Patel, V.R.; Hofstetter, W.L.; Correa, A.M.; Agarwal, A.; Rashid, A.; Bhutani, M.S.; Lin, S.H.; Ajani, J.A.; Swisher, S.G.; Maru, D.M. Signet Ring Cells in Esophageal Adenocarcinoma Predict Poor Response to Preoperative Chemoradiation. Ann. Thorac. Surg. 2014, 98, 1064-1071. [CrossRef]

11. Murphy, M.B.; Xiao, L.; Patel, V.R.; Maru, D.M.; Correa, A.M.; Amlashi, F.G.; Liao, Z.; Komaki, R.; Lin, S.H.; Skinner, H.D.; et al. Pathological complete response in patients with esophageal cancer after the trimodality approach: The association with baseline variables and survival-The University of Texas MD Anderson Cancer Center experience. Cancer 2017, 123, 4106-4113. [CrossRef] [PubMed]

12. Chirieac, L.R.; Swisher, S.G.; Correa, A.M.; Ajani, J.A.; Komaki, R.R.; Rashid, A.; Hamilton, S.R.; Wu, T.-T. Signet-Ring Cell or Mucinous Histology after Preoperative Chemoradiation and Survival in Patients with Esophageal or Esophagogastric Junction Adenocarcinoma. Clin. Cancer Res. 2005, 11, 2229-2236. [CrossRef] [PubMed]

13. Khan, N.; Donohoe, C.L.; Phillips, A.W.; Griffin, S.M.; Reynolds, J.V. Signet ring gastric and esophageal adenocarcinomas: Characteristics and prognostic implications. Dis. Esophagus 2020, 33. [CrossRef]

14. Ajani, J.A.; Lee, J.; Sano, T.; Janjigian, Y.Y.; Fan, D.; Song, S. Gastric adenocarcinoma. Nat. Rev. Dis. Prim. 2017, 3, 17036. [CrossRef] [PubMed]

15. Fléjou, J.-F. Classification OMS 2010 des tumeurs digestives: La quatrième édition. Ann. de Pathol. 2011, 31, S27-S31. [CrossRef]

16. Ansari, S.; Gantuya, B.; Tuan, V.P.; Yamaoka, Y. Diffuse Gastric Cancer: A Summary of Analogous Contributing Factors for Its Molecular Pathogenicity. Int. J. Mol. Sci. 2018, 19, 2424. [CrossRef]

17. National Comprehensive Cancer Network. NCCN Clinical Practice Guidelines in Oncology. Gastric Cancer. Version 2.2020. 2020 06/02/2020. Available online: www.nccn.org (accessed on 2 June 2020).

18. Marcus, C.; Subramaniam, R.M. PET/Computed Tomography and Precision Medicine. PET Clin. 2017, 12, 437-447. [CrossRef]

19. $\mathrm{Wu}, \mathrm{C.}-\mathrm{X}$.; Zhu, Z.-H. Diagnosis and evaluation of gastric cancer by positron emission tomography. World, J. Gastroenterol. 2014, 20, 4574-4585. [CrossRef]

20. Stahl, A.; Ott, K.; Weber, W.A.; Becker, K.; Link, T.; Siewert, J.-R.; Schwaiger, M.; Fink, U. FDG PET imaging of locally advanced gastric carcinomas: Correlation with endoscopic and histopathological findings. Eur. J. Nucl. Med. Mol. Imaging 2003, 30, 288-295. [CrossRef]

21. Kawamura, T.; Kusakabe, T.; Sugino, T.; Watanabe, K.; Fukuda, T.; Nashimoto, A.; Honma, K.; Suzuki, T. Expression of glucose transporter-1 in human gastric carcinoma: Association with tumor aggressiveness, metastasis, and patient survival. Cancer 2001, 92, 634-641. [CrossRef]

22. Chon, H.J.; Kim, C.; Cho, A.; Kim, Y.M.; Jang, S.J.; Kim, B.O.; Park, C.H.; Hyung, W.J.; Ahn, J.B.; Noh, S.H.; et al. The clinical implications of FDG-PET/CT differ according to histology in advanced gastric cancer. Gastric Cancer 2019, 22, 113-122. [CrossRef] [PubMed]

23. Elimova, E.; Ajani, J.A. Surgical Resection First for Localized Gastric Adenocarcinoma: Are There Adjuvant Options? J. Clin. Oncol. 2015, 33, 3085-3091. [CrossRef] [PubMed]

24. Eisenhauer, E.A.; Therasse, P.; Bogaerts, J.; Schwartz, L.H.; Sargent, D.; Ford, R.; Dancey, J.; Arbuck, S.; Gwyther, S.; Mooney, M.; et al. New response evaluation criteria in solid tumours: Revised RECIST guideline (version 1.1). Eur. J. Cancer 2009, 45, $228-247$. [CrossRef] [PubMed]

25. Schwartz, L.H.; Litière, S.; De Vries, E.G.E.; Ford, R.; Gwyther, S.; Mandrekar, S.; Shankar, L.; Bogaerts, J.; Chen, A.; Dancey, J.; et al. RECIST 1.1-Update and clarification: From the RECIST committee. Eur. J. Cancer 2016, 62, 132-137. [CrossRef] [PubMed]

26. Amin, M.B.; Greene, F.L.; Edge, S.B.; Compton, C.C.; Gershenwald, J.E.; Brookland, R.K.; Meyer, L.; Gress, D.M.; Byrd, D.R.; Winchester, D.P. The Eighth Edition AJCC Cancer Staging Manual: Continuing to build a bridge from a population-based to a more "personalized" approach to cancer staging. CA A cancer J. Clin. 2017, 67, 93-99. [CrossRef] [PubMed]

27. Siegel, R.L.; Miller, K.D.; Jemal, A. Cancer statistics. CA A Cancer J. Clin. 2016, 66, 7-30. [CrossRef]

28. Arnold, M.; Ferlay, J.; Henegouwen, M.I.V.B.; Soerjomataram, I. Global burden of oesophageal and gastric cancer by histology and subsite in 2018. Gut 2020, 69, 1564-1571. [CrossRef]

29. Rawla, P.; Barsouk, A. Epidemiology of gastric cancer: Global trends, risk factors and prevention. Gastroenterol. Rev. 2019, 14, 26-38. [CrossRef] 
30. Chon, H.J.; Hyung, W.J.; Kim, C.; Park, S.; Kim, J.-H.; Park, C.H.; Ahn, J.B.; Kim, H.; Chung, H.C.; Rha, S.Y.; et al. Differential Prognostic Implications of Gastric Signet Ring Cell Carcinoma. Ann. Surg. 2017, 265, 946-953. [CrossRef]

31. Charalampakis, N.; Xiao, L.; Elimova, E.; Wadhwa, R.; Shiozaki, H.; Shimodaira, Y.; Blum, M.A.; Planjery, V.; Rogers, J.E.; Matamoros, A.; et al. Initial Standardized Uptake Value of Positron Emission Tomography Influences the Prognosis of Patients with Localized Gastric Adenocarcinoma Treated Preoperatively. Oncology 2015, 89, 305-310. [CrossRef]

32. Ajani, J.A.; D'Amico, T.A.; Bentrem, D.J.; Chao, J.; Corvera, C.; Das, P.; Denlinger, C.S.; Enzinger, P.C.; Fanta, P.; Farjah, F.; et al. Esophageal and Esophagogastric Junction Cancers, Version 2.2019, NCCN Clinical Practice Guidelines in Oncology. J. Natl. Compr. Cancer Netw. 2019, 17, 855-883. [CrossRef] [PubMed]

33. Arslan, E.; Aksoy, T.; Gündoğan, C.; Şen, Ç.; Tatar, S.Y.; Dursun, N.; Çermik, T.F. Metabolic Characteristics and Diagnostic Contribution of 18F-FDG PET/CT in Gastric Carcinomas. Mol. Imaging Radionucl. Ther. 2020, 29, 25-32. [CrossRef] [PubMed] 